\title{
Morphology of the second instar of Diaspidiotus ostreaeformis (CURTIS, 1843) (Hemiptera: Diaspididae)
}

\author{
ELŻBIETA PODSIADŁO* \\ ${ }^{1}$ Department of Zoology, Warsaw University of Life Sciences SGGW, Ciszewskiego 8, \\ 02-786 Warsaw, Poland
}

\begin{abstract}
The second instar of Diaspidiotus ostreaeformis is redescribed and illustrated. Dimorphic characters are presented. It is shown that in both sexes of this species the numbers of long macroducts differ in specimens from different host-plants.
\end{abstract}

KEY WORDS: Hemiptera, Diaspididae, second instar, morphology, sexual dimorphism.

\section{INTRODUCTION}

Data on the morphology of the second instar of Diaspidiotus ostreaeformis (CURTIS, 1843) have been reported by just a few workers. THIEM \& GERNECK (1934), whose observations were only of females, showed that in the second instar of this species the numbers of long macroducts differed in specimens from different host-plants. BORATYŃSKI (1953) was the first to demonstrate sexual dimorphism in the second instar of $D$. ostreaeformis. This author noticed the better developed glandular system in males and also the differences in the body shape of the two sexes. BROOKES \& HUDSON (1968) described the second instar of this species from Australia, but without distinguishing the sexes. STOETZEL \& DAVIDSON (1974a, 1974b) discovered a setal pattern that distinguished the sex in all stages of Aspidiotini: males had a pair of dorsal submedial setae on the $1^{\text {st }}$ and $2^{\text {nd }}$ abdominal segments, whereas in females these setae were absent. PODSIADŁO (2000) noticed a sexual difference in the distribution of setae on the ventral side of the head in the second instar of

\footnotetext{
* Corresponding author: elzbieta_podsiadlo@sggw.pl
} 
Diaspidiotus zonatus (FRAUENFELD, 1868): males had three pairs of setae between the antennae and the anterior margin of the clypeolabral shield, but females had no setae. The same character occurred in the second instar of Parlatoria ziziphi (LUCAS, 1853) (PoDSIADŁO \& BUGILA 2008).

The purpose of this study was to describe the second instar males and females of $D$. ostreaeformis and to update the description of their dimorphic characters.

\section{MATERIALS AND METHODS}

Second instar larvae - from newly emerged to fully-grown ones - were collected from Malus domestica BORKH. on 6.10.2008 and 20.08.2009 in Warsaw, and from Betula pendula ROTH. on 1.03.2009, 15.03.2009 and 9.08.2009 in the Kampinos National Park near Warsaw. Slide mounts were made of 10 male specimens and 7 female specimens from the apple tree, and of 14 male specimens and 24 female specimens from the birch tree.

The numbers of setae and other structures are given for one body half. Measurements in micrometres $(\mu \mathrm{m})$ are given as averages followed by ranges in parentheses.

\section{DESCRIPTION}

\section{Male second instar nymph}

(Figs. 1a, 1b, 2, 4a)

Test grey, slightly convex, nearly circular in young specimens (Fig. 1a), broadly oval in old ones (Fig. 1b); exuviae subcentral, orange-yellow. Length from $960 \mu \mathrm{m}$ to $1410 \mu \mathrm{m}$, width from $700 \mu \mathrm{m}$ to $940 \mu \mathrm{m}$.

Body of live individuals yellow, membranous with brownish, fairly well sclerotized pygidium. Young specimens nearly circular (Fig. 2), tapering slightly posteriorly, becoming elongate with age (Fig. 4a). Length of slide-mounted specimens from $400 \mu \mathrm{m}$ to $805 \mu \mathrm{m}$, width from $310 \mu \mathrm{m}$ to $470 \mu \mathrm{m}$.

Eyes very inconspicuous in young specimens, visible as one pair of small marginal projections, but very conspicuous in fully grown ones, visible as two pairs of ventral dark brown pigmented eyespots; not visible in cleared and stained specimens. 


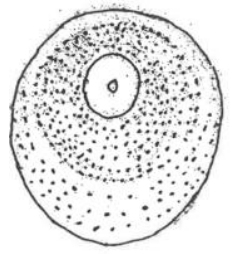

a

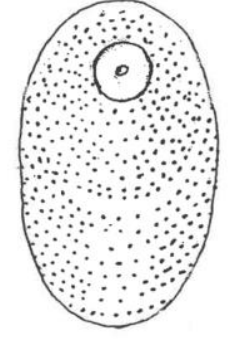

b

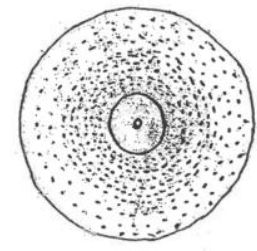

c

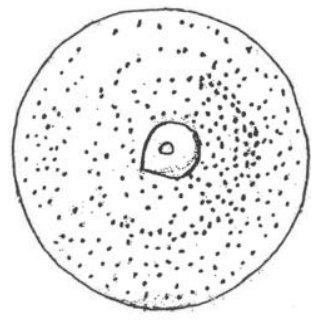

d

Fig.1. Tests of the second instar larvae of Diaspidiotus ostreaeformis a - younger second instar male, b - older second instar male, c - younger second instar female, $\mathrm{d}$ - older second instar female.

Pygidial margin. Sides of pygidium rounded, with blunt apex and three pairs of sclerotized lobes. Median lobes $\left(\mathrm{L}_{1}\right)$ large, distinctly notched on outer margin. Second lobes $\left(\mathrm{L}_{2}\right)$ smaller, with sloping outer margin. Third lobes $\left(\mathrm{L}_{3}\right)$ weakly developed, indicated by small sclerotized process. Plates: 1 very slender, simple or shallowly divided at tip on segment $8 ; 2$ between median and second lobes, the inner being simple or bifid, the outer furcate; 2 or 1 wide between second and third lobes, more or less ramified.

Dorsal surface. Head, pro-, meso- and metathorax not clearly differentiated; abdominal segments 1-4 fairly well defined by intersegmental dermal furrows; subsequent segments fused to form pygidium.

Anal opening nearly circular, ca. $10 \mu \mathrm{m}$ in diameter, located dorsomedially at a distance of about 3.5 times its length from apex of median lobes.

Marginal setae: ca. 5 on head, variable numbers occupying margin of either dorsal or ventral surface, 2 on each thoracic segment, and 1 on each of abdominal segments 1-8. Marginal seta of abdominal segment 9 placed anteriorly to seta of segment 8. Submarginal setae: 2 on head and 1 on prothorax. Mesolateral setae: 1 short on each meso- and metathorax. Submedian setae: 3 on head, 1 short on each thoracic segment and on each of abdominal segments 1-2.

Macroducts. Two types: short and long. Short macroducts arranged in marginal series of 2 ducts, exceptionally 1 duct, on mesothorax; 2 , rarely 3 , ducts on metathorax; a single duct on $1^{\text {st }}$ abdominal segment. In all, there are 5 short macroducts on each side of the body. 


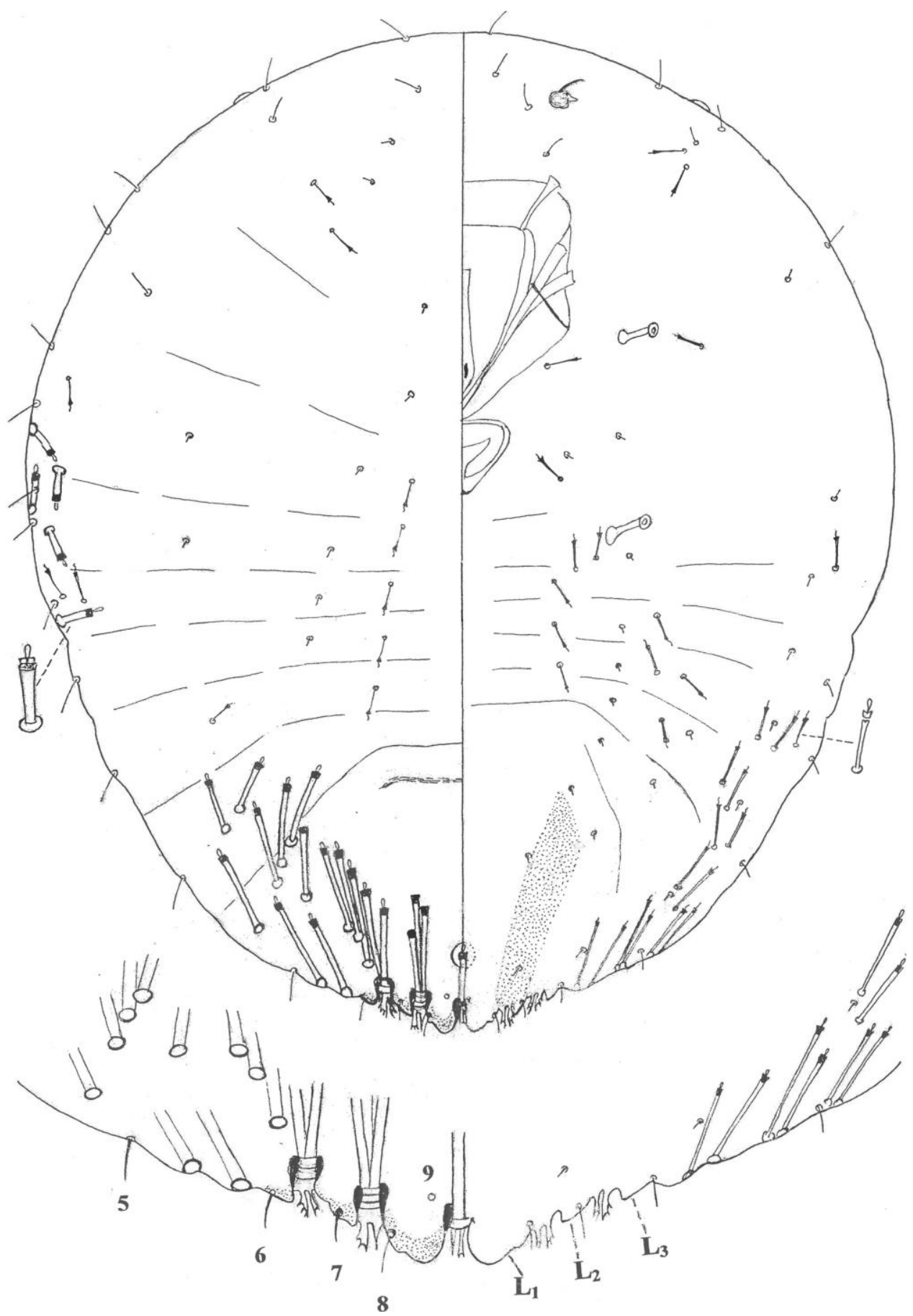

Fig. 2. Second instar male of Diaspidiotus ostreaeformis. 


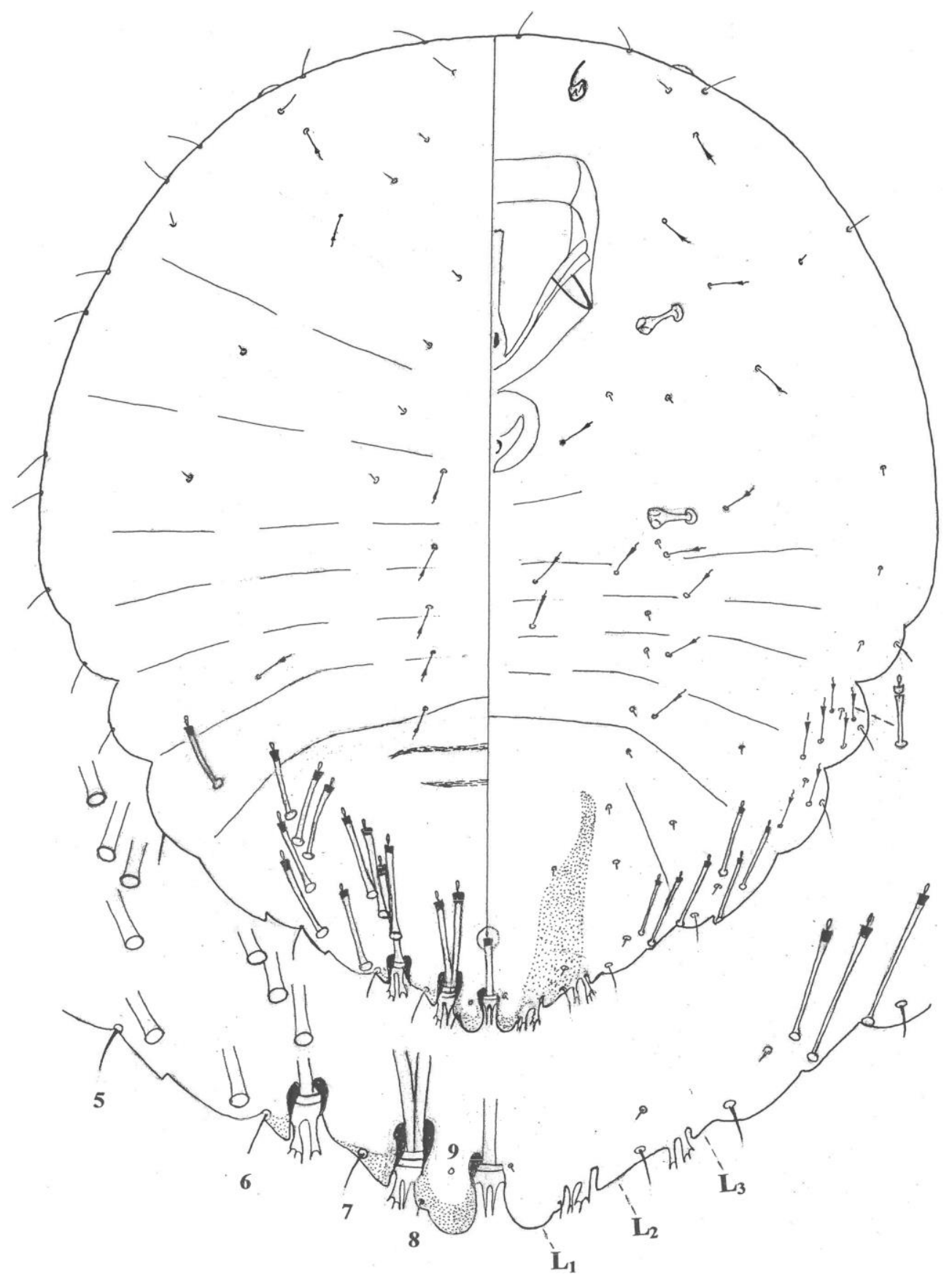

Fig. 3. Second instar female of Diaspidiotus ostreaeformis. 


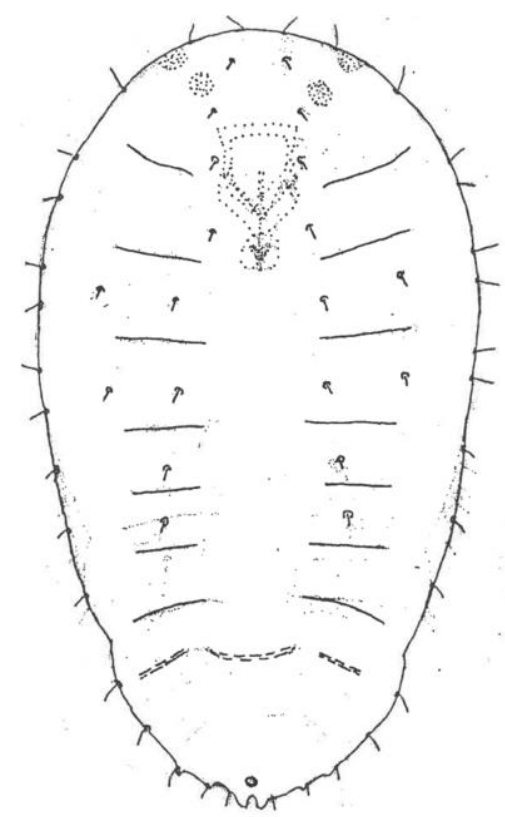

a

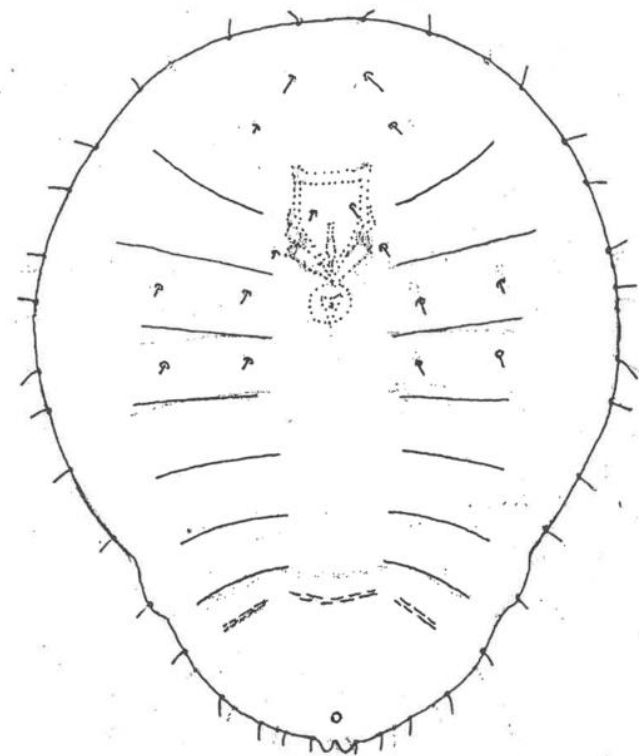

b

Fig. 4. Fully-grown second instar larvae of Diaspidiotus ostreaeformis a-male, b - female; the dorsal setal patterns distinguish the sexes of the second instars.

Long macroducts on each side of the pygidium are distributed as follows: 1-2 on $4^{\text {th }}$ abdominal segment; 5-8 on $5^{\text {th }}$ abdominal segment arranged in a curved oblique row; 4-6 on $6^{\text {th }}$ abdominal segment in oblique row; $2-3$ on $7^{\text {th }}$ abdominal segment in marginal cluster, and a single duct between median lobes extending to anus. The number of long macroducts varies not only individually but also on the two sides of the same insect. The specimens from Malus had fewer long macroducts than those from Betula. On both halves of the pygidium the former had 30-35 (av. 32.5) ducts, the latter 32-37 (av. 34.7).

Microducts. 2 on head in variable positions. A few in marginal and sublateral areas of thoracic and prepygidial abdominal segments. Others distributed in submedian series extending from mesothorax to $3^{\text {rd }}$ abdominal segment.

Ventral surface. Segmentation less distinct than on dorsal side.

Antennae reduced to small tubercles with long stout seta at base.

Clypeolabral shield 105-110 (104.1) $\mu \mathrm{m}$ long, 85-90 (86.6) $\mu \mathrm{m}$ wide. Labium onesegmented 35 (35) $\mu \mathrm{m}$ long, 40 (40) $\mu \mathrm{m}$ wide.

Legs absent. 
Meso- and metathoracic spiracles present. Mesothoracic spiracles displaced anteriorly on prothorax.

Marginal setae: Variable in number on head (see: dorsal surface), 1 on prothorax and 1 on each of abdominal segments 2-8. Submarginal setae: 1 on head, 1 short on pro- and metathorax, and on each of abdominal segments 1-8; Mesolateral setae: 1 short on each of abdominal segments 4-6. Submedian setae: 3 on head anterior to clypeolabral shield, 2 short on mesothorax, 1 on metathorax and 1 on each of abdominal segments 2-7.

Microducts. A few scattered on prosoma; on abdomen distributed in a wide marginal area, in a short submedian series, and sometimes in sublateral area.

\section{Female second instar nymph}

(Figs. 1c, 1d, 3, 4b)

Test grey, slightly convex, circular in both young and old specimens (Figs. 1c, 1d), 920$1370 \mu \mathrm{m}$ in diameter; exuviae central, orange-yellow.

Body of young specimens nearly circular (Fig. 3), similar in shape to young males, but not identical (relatively wider); with age changes shape, becoming pyriform (Fig. 4b). Body colour of live individuals as in males. Length of slide-mounted specimens from $390 \mu \mathrm{m}$ to $720 \mu \mathrm{m}$, width from $340 \mu \mathrm{m}$ to $565 \mu \mathrm{m}$. Eyes often visible in young specimens but not in old ones or in cleared, stained specimens.

Body segmentation as in male.

Setal distribution distinctly different from that of male: pair of dorsal submedial setae on abdominal segments 1 and 2 absent; ventral submedial setae on head between antennae and anterior margin of clypeolabral shield also absent.

Glandular system considerably less developed than in male. Short macroducts absent. Long macroducts less numerous, distributed on each side of the pygidium as follows: 1-2 on $4^{\text {th }}$ abdominal segment; $3-6$ on $5^{\text {th }}$ abdominal segment arranged in curved oblique row; $3-5$ on $6^{\text {th }}$ abdominal segment in oblique row; 2 on $7^{\text {th }}$ abdominal segment in marginal cluster and a single duct between median lobes extending to anus. Specimens from Malus with fewer long macroducts than those from Betula. On both halves of the pygidium the former had 21-27 (av. 23.8) ducts, the latter 25-31 (av. 27.2) ducts. Microducts slightly reduced.

Other morphological structures as in male. 


\section{NOTES}

Sexual dimorphism in the second instar of $D$. ostreaeformis is exhibited in several characteristics. The differences relate to the test shape, position of exuviae, body shape, distribution of setae and degree of development of the glandular system. The differences in the test and body shape are most distinct in fully grown specimens.

The test of young males is nearly circular, that of old ones is broadly oval; exuviae are positioned subcentrally. The tests of both young and old females are circular; exuviae are positioned centrally.

The body of young males is nearly circular, becoming elongate with age. The body of young females is also nearly circular, but slightly wider than in males, becoming pyriform with age.

Males but not females have a pair of dorsal submedial setae on the $1^{\text {st }}$ and $2^{\text {nd }}$ abdominal segments.

Males have three pairs of ventral submedial setae on the head between the antennae and the anterior margin of the clypeolabral shield; in females these setae are absent.

Males have a better developed glandular system: there are more long macroducts and short macroducts are present. The latter are absent in females.

This study has confirmed the results of THIEM \& GERNECK (1934), namely, that the numbers of long macroducts in $2^{\text {nd }}$ instars of $D$. ostreaeformis differ in specimens from different host-plants.

\section{REFERENCES}

BORATYŃSKI K.L. 1953. Sexual dimorphism in the second instar of some Diaspididae (Homoptera: Coccoidea). Transactions of the Royal Entomological Society of London, 104 (12): 451-479.

BRoOKes H.M., HudsOn N.M. 1968. The identification and distribution of Quadraspidiotus species (Homoptera: Diaspididae) on pome and stone fruits in Australia. Journal of the Australian Entomological Society, 7 (2): 90-100.

CURTIS J. (RURICOLA) 1843. Aspidiotus ostreaeformis (the pear-tree oysterscale). Gardeners' Chronicle, 46: 805.

PODSIADŁo E. 2000. Morphology of the second instar larva of Quadraspidiotus zonatus (Hemiptera: Coccinea: Diaspididae). Polish Journal of Entomology, 69 (4): 397-404.

Podsiadło E., Bugila A.A.A. 2008. Morphology of the second-instar males of Parlatoria ziziphi (LuCAS). [in:] M. Branco, J. Carlos, C. Hodgson (eds.). Proceedings of the XI International Symposium on Scale Insect Studies, Oeiras, Portugal, 24-27 September 2007, ISA Press, Lisbon, $51-53$.

Stoetzel M.B., Davidson J.A. 1974a. Sexual dimorphism in all stages of the Aspidiotini (Homoptera: Diaspididae). Annals of the Entomological Society of America, 67 (1): 138-140. 
Stoetzel M.B., DAVidSon J.A. 1974b. Biology, morphology and taxonomy of immature stages of 9 species in the Aspidiotini (Homoptera: Diaspididae). Annals of the Entomological Society of America, 67 (3): 475-509.

THIEM H., GERNECK R. 1934. Untersuchungen an den deutschen Austernschildläusen (Aspidiotini) im Vergleich mit der San José Schildlaus (Aspidiotus perniciosus CoMST.). Arbeiten über morphologische und taxonomische Entomologie aus Berlin-Dahlem, 1 (2): 130-158, 1 (3): 208-238.

Received: 30 July 2018

Accepted: 21 September 2018 